\title{
Factors Affecting Delay Discounting-The Real Option Approach
}

\author{
Eric A. L. $\mathrm{Li}^{1}$ \\ ${ }^{1}$ Department of Statistics and Actuarial Science, University of Hong Kong, Hong Kong, China \\ Correspondence: Eric A. L. Li, Department of Statistics and Actuarial Science, University of Hong Kong, \\ Pokfulam Road, Hong Kong, China. Tel: 86-852-3917-8142. E-mail: ericli11@hku.hk
}

Received: March 6, 2017

Accepted: March 28, $2017 \quad$ Online Published: April 18, 2017

doi:10.5539/ijps.v9n2p96

URL: http://doi.org/10.5539/ijps.v9n2p96

\begin{abstract}
We study factors that can influence Delayed Reward Discounting (DRD) behavior from a novel approach based on economic theory. Real Option (RO) analysis shows that when a decision is irreversible, can be delayed and produces uncertain benefits, then future rewards will be discounted in a way that produces seemingly irrational behavior. In a factorial experimental survey, we asked college students how much they were willing to pay for a digital product when the above factors are involved. Results show that DRD behavior is significantly more manifest when the above factors are present than when absent. We proceeded to calculate the magnitude of this increased DRD behavior that is consistent with predictions from RO theory.
\end{abstract}

Keywords: delay discounting, real option, uncertainty

\section{Introduction}

Delayed Reward Discounting (DRD), also known as hyperbolic discounting, refers to a situation where the value of a future reward is discounted back to the present by a subject using a discount rate that diminishes over time (e.g., Sozou, 1998; Mazur, 1989, 2001; Ainslie, 1975, 2001, 2010; Rachlin, 2000). Almost every individual suffers DRD quantitatively (various discount rates), not qualitatively (yes or no). The serious DRD sufferers often choose short-term but often specious gains over long-term ones (e.g., Dickman, 1990).

The severe form of DRD is often suspected in some pathological behavior or impulsivity such as substance dependence and addictive disorder (e.g., Bickel et al., 1999; Madden et al., 2011; Mackillop et al., 2011; for a thorough review). Bickel et al. (2012) observed that severe DRD has been associated with a wide spectrum of behavioral maladies (e.g., pathological gambling, poor health choices, overeating, etc.). It may be a trans-disease process that occurs across a range of disorders. This makes findings from one disorder relevant to others.

Irrational DRD behavior has also been implicated in economic decision-making such as retirement saving (Thaler \& Benartzi, 2004) and resource allocation over time (Hendrickx et al., 2001). Behavioral economics has been employed to design effective prescriptive programs to remedy the situation (Kahneman \& Tversky, 2000).

Although DRD is always present to a certain extent in an individual, DRD becomes severe enough to render a subject outwardly irrational. Numerous studies have identified factors that can trigger an otherwise mild form of DRD to become significantly problematic. In this paper, we turn to the Real Option (RO) approach in modern economic analysis for an alternative explanation. An RO gives the holder the right but not the obligation (i.e., it is a choice) to undertake a certain project. That is, the project will incur certain costs now and reap the benefits at future dates. If the expected present value of the future benefits exceeds the initial costs, then we go ahead with the project. Otherwise we refrain (e.g., Silberberg \& Suen, 2001). However, when three specific conditions are satisfied (to be mentioned below), we will go ahead only if the expected present value of the future benefits exceeds the initial costs plus the value of an RO (Dixit \& Pindyck, 1994): (1) when the future benefits are uncertain, (2) the initial cost outlays are irreversible (cannot be recouped once expended) and (3) the project can be delayed (it is not now or never). Then the project manager has the option to put the project on hold when the project's earning visibility is too low and the option to go ahead vice versa. The option to be able to do this has an intrinsic value.

The effect of this RO is to make the manager more reluctant to undertake the project now (i.e., procrastinate). He wants to hold out for higher compensation for the loss of this option (Dixit, 1992). Much as the DRD subject would insist on a higher-valued present alternative before he would give up a gamble or substance dependence. 
In the next section, I describe how the RO can be linked to DRD. Section three is an experimental survey that attempts to elicit the RO and the corresponding magnitude of DRD in a consumer behavior setting. Section four summarizes the survey results and section five conducts statistical analysis. Section six concludes and points to some future research directions.

\section{The Real Option Approach}

On a certain level, severe DRD is perhaps synonymous with the reluctance to adopt changes in certain chronic pathological behavior such as gambling, alcohol abuse or procrastination. The idea stems from the traditional benefit-cost analysis. The subject carries through an action when the perceived benefits of the action are greater than its costs. In the 1990s, two economists, A. Dixit and R. Pindyck discovered the RO. When the three above-mentioned pre-conditions are present, the benefits must outweigh the costs by a wide margin to accommodate the value of an RO. The ability to delay an irreversible action when the future benefits are uncertain has a significant value. Furthermore, this option vanishes once it is exercised. Therefore, subjects demand a compensation (Dixit et al., 1999).

Analogously, suppose a consumer is confronted with potentially uncertain benefits from a product offering. He is more reluctant to carry out the purchase now if it is irreversible but can be delayed. He is waiting for a more opportune time when the benefits exceed the costs by the value of a purchase option, before he is willing to let go of/exercise it (e.g., Harrison, 1985; Harrison \& Kreps, 1979). The value of this option now succinctly captures the magnitude of the consumer's DRD. For the consumer to purchase now, he would demand a compensation for the loss of the purchase option. This compensation may be in the form of a discount on his willingness to pay (WTP) for the purchase, i.e., a lowered WTP. How much lower depends on how steep a discount he attaches to the product's price. Hence, the decrease in his WTP is exactly the magnitude of his DRD.

Now suppose that even if the consumer pays full RRP (recommended retail price), the product's benefits are still worth it. However, he will not purchase at RRP now. He wants to delay it because the purchase price may get lower (on account of a future promotional deal). In other words, he procrastinates (Tversky \& Shafir, 1992; Herrmann et al., 2009). He is delaying his purchase because he is discounting the delayed reward (net benefits) of the purchase. That is why he will not buy now even though net benefits are positive. Therefore, DRD seems irrational but not if the reason he delays is because he holds the buy option, and the buy option has value. In that case, the net benefits of the purchase may not be sufficient enough to overcome the option value. The discount in DRD (manifested as a lowered WTP) is to account for the existence of the value of this option. Therefore DRD is due to this option, and the option exists in the presence of uncertainty, irreversibility and delay. Ergo, these are the three factors affecting DRD in this scenario. The survey below will show precisely that this trio of factors must be present simultaneously for the RO to exist, i.e., for DRD to manifest itself.

\section{The Survey}

\subsection{Participants}

To investigate the suppressing effect of an RO on WTP, I carried out a survey at a university in Turkey during the week of May 3 to May 7, 2010. It was a non-exam week. The location was the Faculty of Business and Economics (FBE). Seven interviewers (senior students) were recruited (labeled $a, b, c, d, \mathrm{e}, f, g$ ). Interviewers $a$, $c, d, g$ were male, while $c, e, f$ were female. There were two survey venues: the small cafeteria inside the FBE building and the large Café inside the Central Lectures Hall (CLH). There were a total of five class days. On each day, one interviewer is placed each at FBE and CLH from 0800 to 0830 (morning coffee break before classes start) and from 1200 to 1230 (during lunch break). Therefore, there were a total of 20 survey sessions (two sessions per day $\mathrm{x}$ two venues $\mathrm{x}$ five days). The assignment of interviewers at each location and time slot was random. An interviewer might conduct more than one survey session since there are more sessions (20) than interviewers (seven). The allocation of interviewers can be seen in Table 1 -the survey dataset. 
Table 1. Survey dataset

\begin{tabular}{|c|c|c|c|c|c|c|c|}
\hline WTP & scenario & 16 or $32 \mathrm{~Gb}$ & sex & day & Time & Venue & interviewer \\
\hline 850 & 2 & 16 & $\mathrm{~m}$ & 1 & $0800-0830$ & CLH & $\mathrm{a}$ \\
\hline 1050 & 3 & 32 & $\mathrm{f}$ & 1 & 0800-0830 & $\mathrm{CLH}$ & $\mathrm{a}$ \\
\hline 900 & 4 & 32 & $\mathrm{f}$ & 1 & 0800-0830 & CLH & $\mathrm{a}$ \\
\hline 890 & 8 & 16 & $\mathrm{~m}$ & 1 & $0800-0830$ & $\mathrm{CLH}$ & $\mathrm{a}$ \\
\hline 1000 & 1 & 32 & $\mathrm{f}$ & 1 & 0800-0830 & CLH & $\mathrm{a}$ \\
\hline 800 & 4 & 32 & $\mathrm{f}$ & 1 & 0800-0830 & CLH & $\mathrm{a}$ \\
\hline 900 & 5 & 16 & $\mathrm{f}$ & 1 & 0800-0830 & CLH & $\mathrm{a}$ \\
\hline 850 & 6 & 16 & $\mathrm{~m}$ & 1 & 0800-0830 & CLH & a \\
\hline 1000 & 2 & 32 & $\mathrm{~m}$ & 1 & 0800-0830 & CLH & $\mathrm{a}$ \\
\hline 1040 & 3 & 32 & $\mathrm{f}$ & 1 & 0800-0830 & CLH & $\mathrm{a}$ \\
\hline 1050 & 2 & 32 & $\mathrm{f}$ & 1 & 0800-0830 & FBE & $\mathrm{b}$ \\
\hline 900 & 3 & 16 & $\mathrm{f}$ & 1 & 0800-0830 & FBE & $\mathrm{b}$ \\
\hline 750 & 4 & 16 & $\mathrm{f}$ & 1 & 0800-0830 & FBE & $\mathrm{b}$ \\
\hline 1100 & 2 & 32 & $\mathrm{~m}$ & 1 & 0800-0830 & FBE & $\mathrm{b}$ \\
\hline 960 & 3 & 16 & $\mathrm{f}$ & 1 & 0800-0830 & FBE & $\mathrm{b}$ \\
\hline 700 & 4 & 16 & $\mathrm{~m}$ & 1 & 0800-0830 & FBE & $\mathrm{b}$ \\
\hline 850 & 5 & 16 & $\mathrm{f}$ & 1 & 0800-0830 & FBE & $\mathrm{b}$ \\
\hline 1050 & 6 & 32 & $\mathrm{f}$ & 1 & 0800-0830 & FBE & $\mathrm{b}$ \\
\hline 900 & 7 & 16 & $\mathrm{f}$ & 1 & $0800-0830$ & FBE & $\mathrm{b}$ \\
\hline 1050 & 8 & 32 & $\mathrm{~m}$ & 1 & 0800-0830 & FBE & $\mathrm{b}$ \\
\hline 900 & 2 & 16 & $\mathrm{f}$ & 1 & 0800-0830 & FBE & $\mathrm{b}$ \\
\hline 880 & 8 & 16 & $\mathrm{~m}$ & 1 & $1200-1230$ & CLH & a \\
\hline 1100 & 5 & 32 & $\mathrm{~m}$ & 1 & $1200-1230$ & $\mathrm{CLH}$ & $\mathrm{a}$ \\
\hline 1010 & 6 & 32 & $\mathrm{~m}$ & 1 & $1200-1230$ & CLH & $\mathrm{a}$ \\
\hline 700 & 4 & 16 & $\mathrm{f}$ & 1 & $1200-1230$ & CLH & $\mathrm{a}$ \\
\hline 900 & 3 & 16 & $\mathrm{~m}$ & 1 & $1200-1230$ & CLH & $\mathrm{a}$ \\
\hline 800 & 4 & 16 & $\mathrm{f}$ & 1 & $1200-1230$ & CLH & $\mathrm{a}$ \\
\hline 1050 & 5 & 32 & $\mathrm{f}$ & 1 & $1200-1230$ & CLH & $\mathrm{a}$ \\
\hline 1000 & 6 & 32 & $\mathrm{f}$ & 1 & $1200-1230$ & CLH & $\mathrm{a}$ \\
\hline 1100 & 7 & 32 & $\mathrm{~m}$ & 1 & $1200-1230$ & CLH & $\mathrm{a}$ \\
\hline 800 & 2 & 16 & $\mathrm{~m}$ & 1 & $1200-1230$ & CLH & $\mathrm{a}$ \\
\hline 1100 & 2 & 32 & $\mathrm{~m}$ & 1 & $1200-1230$ & FBE & $\mathrm{c}$ \\
\hline 1100 & 3 & 32 & $\mathrm{~m}$ & 1 & $1200-1230$ & FBE & $\mathrm{c}$ \\
\hline 850 & 4 & 16 & $\mathrm{f}$ & 1 & $1200-1230$ & FBE & $\mathrm{c}$ \\
\hline 850 & 1 & 16 & $\mathrm{f}$ & 1 & $1200-1230$ & FBE & $\mathrm{c}$ \\
\hline 890 & 6 & 16 & $\mathrm{f}$ & 1 & $1200-1230$ & FBE & $\mathrm{c}$ \\
\hline 1000 & 8 & 32 & $\mathrm{~m}$ & 1 & $1200-1230$ & FBE & $\mathrm{c}$ \\
\hline 1050 & 7 & 32 & $\mathrm{f}$ & 1 & $1200-1230$ & FBE & $\mathrm{c}$ \\
\hline 900 & 5 & 16 & $\mathrm{~m}$ & 1 & $1200-1230$ & FBE & $\mathrm{c}$ \\
\hline 600 & 4 & 16 & $\mathrm{~m}$ & 1 & $1200-1230$ & FBE & $\mathrm{c}$ \\
\hline
\end{tabular}




\begin{tabular}{|c|c|c|c|c|c|c|c|}
\hline 910 & 3 & 16 & $\mathrm{f}$ & 1 & $1200-1230$ & FBE & $\mathrm{c}$ \\
\hline 890 & 3 & 16 & $\mathrm{f}$ & 2 & 0800-0830 & $\mathrm{CLH}$ & $\mathrm{d}$ \\
\hline 600 & 4 & 16 & $\mathrm{f}$ & 2 & 0800-0830 & $\mathrm{CLH}$ & $\mathrm{d}$ \\
\hline 890 & 5 & 16 & $\mathrm{~m}$ & 2 & 0800-0830 & $\mathrm{CLH}$ & d \\
\hline 1000 & 2 & 32 & $\mathrm{~m}$ & 2 & 0800-0830 & $\mathrm{CLH}$ & $\mathrm{d}$ \\
\hline 1100 & 6 & 32 & $\mathrm{~m}$ & 2 & 0800-0830 & $\mathrm{CLH}$ & $\mathrm{d}$ \\
\hline 950 & 8 & 32 & $\mathrm{~m}$ & 2 & 0800-0830 & $\mathrm{CLH}$ & $\mathrm{d}$ \\
\hline 900 & 7 & 16 & $\mathrm{f}$ & 2 & 0800-0830 & $\mathrm{CLH}$ & $\mathrm{d}$ \\
\hline 800 & 1 & 16 & $\mathrm{~m}$ & 2 & 0800-0830 & $\mathrm{CLH}$ & $\mathrm{d}$ \\
\hline 1000 & 2 & 32 & $\mathrm{f}$ & 2 & 0800-0830 & $\mathrm{CLH}$ & $\mathrm{d}$ \\
\hline 700 & 4 & 16 & $\mathrm{f}$ & 2 & 0800-0830 & FBE & $\mathrm{e}$ \\
\hline 1100 & 5 & 32 & $\mathrm{f}$ & 2 & 0800-0830 & FBE & $\mathrm{e}$ \\
\hline 850 & 6 & 16 & $\mathrm{~m}$ & 2 & 0800-0830 & FBE & $\mathrm{e}$ \\
\hline 950 & 2 & 32 & $\mathrm{~m}$ & 2 & 0800-0830 & FBE & e \\
\hline 900 & 3 & 16 & $\mathrm{~m}$ & 2 & 0800-0830 & FBE & $\mathrm{e}$ \\
\hline 800 & 4 & 16 & $\mathrm{f}$ & 2 & 0800-0830 & FBE & $\mathrm{e}$ \\
\hline 1100 & 1 & 32 & $\mathrm{~m}$ & 2 & 0800-0830 & FBE & $\mathrm{e}$ \\
\hline 990 & 8 & 32 & $\mathrm{f}$ & 2 & 0800-0830 & FBE & e \\
\hline 900 & 1 & 16 & $\mathrm{f}$ & 2 & 0800-0830 & FBE & e \\
\hline 1100 & 3 & 32 & $\mathrm{~m}$ & 2 & 0800-0830 & FBE & $\mathrm{e}$ \\
\hline 900 & 4 & 32 & $\mathrm{f}$ & 2 & $1200-1230$ & $\mathrm{CLH}$ & $\mathrm{f}$ \\
\hline 850 & 4 & 32 & $\mathrm{~m}$ & 2 & $1200-1230$ & $\mathrm{CLH}$ & $\mathrm{f}$ \\
\hline 1040 & 5 & 32 & $\mathrm{f}$ & 2 & $1200-1230$ & $\mathrm{CLH}$ & $\mathrm{f}$ \\
\hline 890 & 6 & 16 & $\mathrm{~m}$ & 2 & $1200-1230$ & $\mathrm{CLH}$ & $\mathrm{f}$ \\
\hline 1000 & 2 & 32 & $\mathrm{f}$ & 2 & $1200-1230$ & $\mathrm{CLH}$ & $\mathrm{f}$ \\
\hline 950 & 1 & 16 & $\mathrm{~m}$ & 2 & $1200-1230$ & $\mathrm{CLH}$ & $\mathrm{f}$ \\
\hline 800 & 2 & 16 & $\mathrm{~m}$ & 2 & $1200-1230$ & $\mathrm{CLH}$ & $\mathrm{f}$ \\
\hline 850 & 8 & 16 & $\mathrm{~m}$ & 2 & $1200-1230$ & $\mathrm{CLH}$ & $\mathrm{f}$ \\
\hline 1100 & 7 & 32 & $\mathrm{f}$ & 2 & $1200-1230$ & $\mathrm{CLH}$ & $\mathrm{f}$ \\
\hline 900 & 8 & 16 & $\mathrm{f}$ & 2 & $1200-1230$ & $\mathrm{CLH}$ & $\mathrm{f}$ \\
\hline 650 & 4 & 16 & $\mathrm{f}$ & 2 & $1200-1230$ & FBE & $\mathrm{g}$ \\
\hline 750 & 4 & 16 & $\mathrm{f}$ & 2 & $1200-1230$ & FBE & $\mathrm{g}$ \\
\hline 1080 & 5 & 32 & $\mathrm{~m}$ & 2 & $1200-1230$ & FBE & $\mathrm{g}$ \\
\hline 1070 & 6 & 32 & $\mathrm{f}$ & 2 & $1200-1230$ & FBE & $\mathrm{g}$ \\
\hline 900 & 2 & 16 & $\mathrm{f}$ & 2 & $1200-1230$ & FBE & $\mathrm{g}$ \\
\hline 920 & 3 & 16 & $\mathrm{~m}$ & 2 & $1200-1230$ & FBE & $\mathrm{g}$ \\
\hline 900 & 1 & 16 & $\mathrm{f}$ & 2 & $1200-1230$ & FBE & $\mathrm{g}$ \\
\hline 900 & 8 & 16 & $\mathrm{~m}$ & 2 & $1200-1230$ & FBE & $\mathrm{g}$ \\
\hline 1050 & 7 & 32 & $\mathrm{f}$ & 2 & $1200-1230$ & FBE & $\mathrm{g}$ \\
\hline 950 & 2 & 32 & $\mathrm{~m}$ & 2 & $1200-1230$ & FBE & $\mathrm{g}$ \\
\hline 1000 & 1 & 32 & $\mathrm{~m}$ & 2 & $1200-1230$ & FBE & $\mathrm{g}$ \\
\hline 850 & 2 & 16 & $\mathrm{~m}$ & 3 & 0800-0830 & $\mathrm{CLH}$ & $\mathrm{g}$ \\
\hline
\end{tabular}




\begin{tabular}{|c|c|c|c|c|c|c|c|}
\hline 880 & 2 & 16 & $\mathrm{~m}$ & 3 & 0800-0830 & $\mathrm{CLH}$ & $\mathrm{g}$ \\
\hline 780 & 4 & 16 & $\mathrm{f}$ & 3 & 0800-0830 & $\mathrm{CLH}$ & $\mathrm{g}$ \\
\hline 890 & 1 & 16 & $\mathrm{~m}$ & 3 & 0800-0830 & $\mathrm{CLH}$ & $\mathrm{g}$ \\
\hline 990 & 6 & 32 & $\mathrm{f}$ & 3 & 0800-0830 & $\mathrm{CLH}$ & $\mathrm{g}$ \\
\hline 1000 & 7 & 32 & $\mathrm{f}$ & 3 & 0800-0830 & $\mathrm{CLH}$ & $\mathrm{g}$ \\
\hline 690 & 4 & 16 & $\mathrm{~m}$ & 3 & 0800-0830 & $\mathrm{CLH}$ & $\mathrm{g}$ \\
\hline 890 & 5 & 16 & $\mathrm{f}$ & 3 & 0800-0830 & $\mathrm{CLH}$ & $\mathrm{g}$ \\
\hline 1050 & 8 & 32 & $\mathrm{f}$ & 3 & 0800-0830 & $\mathrm{CLH}$ & g \\
\hline 1050 & 5 & 32 & $\mathrm{f}$ & 3 & 0800-0830 & $\mathrm{CLH}$ & $\mathrm{g}$ \\
\hline 900 & 2 & 16 & $\mathrm{~m}$ & 3 & 0800-0830 & FBE & $\mathrm{c}$ \\
\hline 720 & 4 & 16 & $\mathrm{f}$ & 3 & 0800-0830 & FBE & $\mathrm{c}$ \\
\hline 1050 & 3 & 32 & $\mathrm{~m}$ & 3 & 0800-0830 & FBE & $\mathrm{c}$ \\
\hline 1030 & 5 & 32 & $\mathrm{f}$ & 3 & 0800-0830 & FBE & $\mathrm{c}$ \\
\hline 880 & 6 & 16 & $\mathrm{~m}$ & 3 & 0800-0830 & FBE & $\mathrm{c}$ \\
\hline 900 & 7 & 16 & $\mathrm{f}$ & 3 & 0800-0830 & FBE & $\mathrm{c}$ \\
\hline 950 & 8 & 32 & $\mathrm{~m}$ & 3 & 0800-0830 & FBE & $\mathrm{c}$ \\
\hline 900 & 1 & 16 & $\mathrm{f}$ & 3 & 0800-0830 & FBE & $\mathrm{c}$ \\
\hline 870 & 2 & 16 & $\mathrm{f}$ & 3 & 0800-0830 & FBE & $\mathrm{c}$ \\
\hline 1100 & 3 & 32 & $\mathrm{f}$ & 3 & 0800-0830 & FBE & $\mathrm{c}$ \\
\hline 900 & 5 & 16 & $\mathrm{~m}$ & 3 & 0800-0830 & FBE & $\mathrm{c}$ \\
\hline 1000 & 3 & 32 & $\mathrm{~m}$ & 3 & 0800-0830 & FBE & $\mathrm{c}$ \\
\hline 900 & 3 & 16 & $\mathrm{f}$ & 3 & $1200-1230$ & $\mathrm{CLH}$ & d \\
\hline 750 & 4 & 16 & $\mathrm{~m}$ & 3 & $1200-1230$ & $\mathrm{CLH}$ & d \\
\hline 880 & 3 & 16 & $\mathrm{f}$ & 3 & $1200-1230$ & $\mathrm{CLH}$ & $\mathrm{d}$ \\
\hline 1100 & 2 & 32 & $\mathrm{f}$ & 3 & $1200-1230$ & $\mathrm{CLH}$ & $\mathrm{d}$ \\
\hline 1050 & 1 & 32 & $\mathrm{~m}$ & 3 & $1200-1230$ & $\mathrm{CLH}$ & $\mathrm{d}$ \\
\hline 1060 & 5 & 32 & $\mathrm{f}$ & 3 & $1200-1230$ & $\mathrm{CLH}$ & $\mathrm{d}$ \\
\hline 810 & 4 & 16 & $\mathrm{~m}$ & 3 & $1200-1230$ & $\mathrm{CLH}$ & $\mathrm{d}$ \\
\hline 1100 & 7 & 32 & $\mathrm{f}$ & 3 & $1200-1230$ & $\mathrm{CLH}$ & $\mathrm{d}$ \\
\hline 1030 & 8 & 32 & $\mathrm{f}$ & 3 & $1200-1230$ & $\mathrm{CLH}$ & $\mathrm{d}$ \\
\hline 900 & 4 & 32 & $\mathrm{~m}$ & 3 & $1200-1230$ & $\mathrm{CLH}$ & $\mathrm{d}$ \\
\hline 900 & 1 & 16 & $\mathrm{f}$ & 3 & $1200-1230$ & FBE & $\mathrm{b}$ \\
\hline 900 & 2 & 16 & $\mathrm{~m}$ & 3 & $1200-1230$ & FBE & $\mathrm{b}$ \\
\hline 800 & 4 & 16 & $\mathrm{f}$ & 3 & $1200-1230$ & FBE & $\mathrm{b}$ \\
\hline 900 & 5 & 16 & $\mathrm{~m}$ & 3 & $1200-1230$ & FBE & $\mathrm{b}$ \\
\hline 865 & 6 & 16 & $\mathrm{f}$ & 3 & $1200-1230$ & FBE & $\mathrm{b}$ \\
\hline 1050 & 7 & 32 & $\mathrm{~m}$ & 3 & $1200-1230$ & FBE & $\mathrm{b}$ \\
\hline 1100 & 8 & 32 & $\mathrm{~m}$ & 3 & $1200-1230$ & FBE & $\mathrm{b}$ \\
\hline 865 & 5 & 16 & $\mathrm{~m}$ & 3 & $1200-1230$ & FBE & $\mathrm{b}$ \\
\hline 1100 & 1 & 32 & $\mathrm{f}$ & 3 & $1200-1230$ & FBE & $\mathrm{b}$ \\
\hline 1100 & 2 & 32 & $\mathrm{f}$ & 3 & $1200-1230$ & FBE & $\mathrm{b}$ \\
\hline 850 & 2 & 16 & $\mathrm{f}$ & 4 & 0800-0830 & $\mathrm{CLH}$ & $\mathrm{f}$ \\
\hline
\end{tabular}




\begin{tabular}{|c|c|c|c|c|c|c|c|}
\hline 900 & 3 & 16 & $\mathrm{f}$ & 4 & 0800-0830 & $\mathrm{CLH}$ & $\mathrm{f}$ \\
\hline 900 & 2 & 16 & f & 4 & 0800-0830 & $\mathrm{CLH}$ & $\mathrm{f}$ \\
\hline 1000 & 4 & 32 & $\mathrm{~m}$ & 4 & 0800-0830 & $\mathrm{CLH}$ & $\mathrm{f}$ \\
\hline 800 & 4 & 16 & $\mathrm{~m}$ & 4 & 0800-0830 & $\mathrm{CLH}$ & $\mathrm{f}$ \\
\hline 1055 & 5 & 32 & $\mathrm{f}$ & 4 & 0800-0830 & $\mathrm{CLH}$ & $\mathrm{f}$ \\
\hline 900 & 6 & 16 & $\mathrm{f}$ & 4 & 0800-0830 & $\mathrm{CLH}$ & $\mathrm{f}$ \\
\hline 1050 & 1 & 32 & $\mathrm{~m}$ & 4 & 0800-0830 & $\mathrm{CLH}$ & $\mathrm{f}$ \\
\hline 1060 & 7 & 32 & $\mathrm{~m}$ & 4 & 0800-0830 & $\mathrm{CLH}$ & $\mathrm{f}$ \\
\hline 910 & 8 & 16 & $\mathrm{~m}$ & 4 & 0800-0830 & $\mathrm{CLH}$ & $\mathrm{f}$ \\
\hline 800 & 2 & 16 & $\mathrm{f}$ & 4 & 0800-0830 & FBE & $\mathrm{c}$ \\
\hline 900 & 1 & 16 & $\mathrm{~m}$ & 4 & 0800-0830 & FBE & $\mathrm{c}$ \\
\hline 1000 & 2 & 32 & $\mathrm{f}$ & 4 & 0800-0830 & FBE & $\mathrm{c}$ \\
\hline 950 & 4 & 32 & $\mathrm{~m}$ & 4 & 0800-0830 & FBE & $\mathrm{c}$ \\
\hline 910 & 6 & 16 & $\mathrm{f}$ & 4 & 0800-0830 & FBE & $\mathrm{c}$ \\
\hline 910 & 7 & 16 & $\mathrm{f}$ & 4 & 0800-0830 & FBE & $\mathrm{c}$ \\
\hline 1050 & 8 & 32 & $\mathrm{~m}$ & 4 & 0800-0830 & FBE & $\mathrm{c}$ \\
\hline 1100 & 6 & 32 & $\mathrm{~m}$ & 4 & 0800-0830 & FBE & $\mathrm{c}$ \\
\hline 1020 & 7 & 32 & $\mathrm{~m}$ & 4 & 0800-0830 & FBE & $\mathrm{c}$ \\
\hline 900 & 8 & 16 & $\mathrm{f}$ & 4 & 0800-0830 & FBE & $\mathrm{c}$ \\
\hline 900 & 4 & 32 & $\mathrm{f}$ & 4 & 0800-0830 & FBE & $\mathrm{c}$ \\
\hline 1100 & 3 & 32 & $\mathrm{f}$ & 4 & $1200-1230$ & $\mathrm{CLH}$ & $\mathrm{b}$ \\
\hline 920 & 5 & 16 & $\mathrm{~m}$ & 4 & $1200-1230$ & $\mathrm{CLH}$ & $\mathrm{b}$ \\
\hline 1100 & 1 & 32 & $\mathrm{~m}$ & 4 & $1200-1230$ & $\mathrm{CLH}$ & $\mathrm{b}$ \\
\hline 900 & 6 & 16 & $\mathrm{~m}$ & 4 & $1200-1230$ & $\mathrm{CLH}$ & $\mathrm{b}$ \\
\hline 910 & 7 & 16 & $\mathrm{f}$ & 4 & $1200-1230$ & $\mathrm{CLH}$ & $\mathrm{b}$ \\
\hline 890 & 8 & 16 & $\mathrm{~m}$ & 4 & $1200-1230$ & $\mathrm{CLH}$ & $\mathrm{b}$ \\
\hline 1100 & 8 & 32 & $\mathrm{f}$ & 4 & $1200-1230$ & $\mathrm{CLH}$ & $\mathrm{b}$ \\
\hline 920 & 1 & 16 & $\mathrm{f}$ & 4 & $1200-1230$ & $\mathrm{CLH}$ & $\mathrm{b}$ \\
\hline 700 & 4 & 16 & $\mathrm{f}$ & 4 & $1200-1230$ & $\mathrm{CLH}$ & $\mathrm{b}$ \\
\hline 1010 & 5 & 32 & $\mathrm{~m}$ & 4 & $1200-1230$ & $\mathrm{CLH}$ & $\mathrm{b}$ \\
\hline 900 & 3 & 16 & $\mathrm{f}$ & 4 & $1200-1230$ & FBE & $\mathrm{a}$ \\
\hline 800 & 2 & 16 & $\mathrm{~m}$ & 4 & $1200-1230$ & FBE & $\mathrm{a}$ \\
\hline 890 & 3 & 16 & $\mathrm{f}$ & 4 & $1200-1230$ & FBE & $\mathrm{a}$ \\
\hline 1040 & 5 & 32 & $\mathrm{f}$ & 4 & $1200-1230$ & FBE & $\mathrm{a}$ \\
\hline 1050 & 6 & 32 & $\mathrm{~m}$ & 4 & $1200-1230$ & FBE & $\mathrm{a}$ \\
\hline 900 & 7 & 16 & $\mathrm{~m}$ & 4 & $1200-1230$ & FBE & $\mathrm{a}$ \\
\hline 900 & 4 & 32 & $\mathrm{f}$ & 4 & $1200-1230$ & FBE & $\mathrm{a}$ \\
\hline 1000 & 5 & 32 & $\mathrm{f}$ & 4 & $1200-1230$ & FBE & $\mathrm{a}$ \\
\hline 900 & 1 & 16 & $\mathrm{f}$ & 4 & $1200-1230$ & FBE & $\mathrm{a}$ \\
\hline 1060 & 7 & 32 & $\mathrm{~m}$ & 4 & $1200-1230$ & FBE & $\mathrm{a}$ \\
\hline 910 & 8 & 16 & $\mathrm{f}$ & 4 & $1200-1230$ & FBE & $\mathrm{a}$ \\
\hline 950 & 3 & 16 & $\mathrm{f}$ & 5 & 0800-0830 & $\mathrm{CLH}$ & d \\
\hline
\end{tabular}




\begin{tabular}{|c|c|c|c|c|c|c|c|}
\hline 800 & 4 & 16 & $\mathrm{~m}$ & 5 & $0800-0830$ & $\mathrm{CLH}$ & $\mathrm{d}$ \\
\hline 900 & 2 & 32 & $\mathrm{~m}$ & 5 & 0800-0830 & CLH & d \\
\hline 1100 & 3 & 32 & $\mathrm{~m}$ & 5 & 0800-0830 & CLH & d \\
\hline 900 & 1 & 16 & $\mathrm{f}$ & 5 & $0800-0830$ & CLH & d \\
\hline 1100 & 6 & 32 & $\mathrm{f}$ & 5 & $0800-0830$ & CLH & d \\
\hline 900 & 7 & 16 & $\mathrm{f}$ & 5 & 0800-0830 & CLH & d \\
\hline 900 & 8 & 16 & $\mathrm{f}$ & 5 & 0800-0830 & CLH & d \\
\hline 700 & 4 & 16 & $\mathrm{~m}$ & 5 & $0800-0830$ & CLH & d \\
\hline 1070 & 5 & 32 & $\mathrm{~m}$ & 5 & 0800-0830 & CLH & d \\
\hline 900 & 3 & 16 & $\mathrm{f}$ & 5 & 0800-0830 & FBE & g \\
\hline 950 & 4 & 32 & $\mathrm{~m}$ & 5 & 0800-0830 & FBE & g \\
\hline 900 & 5 & 16 & $\mathrm{f}$ & 5 & $0800-0830$ & FBE & g \\
\hline 660 & 4 & 16 & $\mathrm{~m}$ & 5 & 0800-0830 & FBE & g \\
\hline 910 & 6 & 16 & $\mathrm{f}$ & 5 & $0800-0830$ & FBE & g \\
\hline 1050 & 7 & 32 & $\mathrm{f}$ & 5 & 0800-0830 & FBE & g \\
\hline 1100 & 8 & 32 & $\mathrm{f}$ & 5 & 0800-0830 & FBE & $\mathrm{g}$ \\
\hline 900 & 7 & 16 & $\mathrm{~m}$ & 5 & 0800-0830 & FBE & $\mathrm{g}$ \\
\hline 1050 & 5 & 32 & $\mathrm{f}$ & 5 & 0800-0830 & FBE & g \\
\hline 905 & 1 & 16 & $\mathrm{~m}$ & 5 & 0800-0830 & FBE & $\mathrm{g}$ \\
\hline 950 & 2 & 32 & $\mathrm{~m}$ & 5 & 0800-0830 & FBE & $\mathrm{g}$ \\
\hline 900 & 2 & 16 & $\mathrm{f}$ & 5 & $1200-1230$ & CLH & $\mathrm{f}$ \\
\hline 1100 & 3 & 32 & $\mathrm{~m}$ & 5 & $1200-1230$ & CLH & $\mathrm{f}$ \\
\hline 1000 & 4 & 32 & $\mathrm{f}$ & 5 & $1200-1230$ & CLH & f \\
\hline 900 & 3 & 16 & $\mathrm{~m}$ & 5 & $1200-1230$ & CLH & f \\
\hline 800 & 4 & 32 & $\mathrm{~m}$ & 5 & $1200-1230$ & CLH & $\mathrm{f}$ \\
\hline 910 & 1 & 16 & $\mathrm{~m}$ & 5 & $1200-1230$ & CLH & $\mathrm{f}$ \\
\hline 900 & 6 & 16 & $\mathrm{f}$ & 5 & $1200-1230$ & CLH & $\mathrm{f}$ \\
\hline 1080 & 7 & 32 & $\mathrm{f}$ & 5 & $1200-1230$ & CLH & $\mathrm{f}$ \\
\hline 1020 & 8 & 32 & $\mathrm{f}$ & 5 & $1200-1230$ & CLH & $\mathrm{f}$ \\
\hline 1060 & 5 & 32 & $\mathrm{~m}$ & 5 & $1200-1230$ & CLH & $\mathrm{f}$ \\
\hline 700 & 4 & 16 & $\mathrm{f}$ & 5 & $1200-1230$ & FBE & $\mathrm{e}$ \\
\hline 900 & 5 & 16 & $\mathrm{~m}$ & 5 & $1200-1230$ & FBE & $\mathrm{e}$ \\
\hline 900 & 7 & 16 & $\mathrm{f}$ & 5 & $1200-1230$ & FBE & $\mathrm{e}$ \\
\hline 1100 & 7 & 32 & $\mathrm{~m}$ & 5 & $1200-1230$ & FBE & $\mathrm{e}$ \\
\hline 760 & 4 & 32 & $\mathrm{f}$ & 5 & $1200-1230$ & FBE & $\mathrm{e}$ \\
\hline 890 & 2 & 16 & $\mathrm{~m}$ & 5 & $1200-1230$ & FBE & $\mathrm{e}$ \\
\hline 1100 & 1 & 32 & $\mathrm{~m}$ & 5 & $1200-1230$ & FBE & $\mathrm{e}$ \\
\hline 990 & 2 & 32 & $\mathrm{f}$ & 5 & $1200-1230$ & FBE & e \\
\hline 910 & 3 & 16 & $\mathrm{f}$ & 5 & $1200-1230$ & FBE & $\mathrm{e}$ \\
\hline 1050 & 2 & 32 & $\mathrm{~m}$ & 5 & $1200-1230$ & FBE & $\mathrm{e}$ \\
\hline 1050 & 8 & 32 & $\mathrm{f}$ & 5 & $1200-1230$ & FBE & e \\
\hline
\end{tabular}




\subsection{Materials and Procedure}

In each session, around ten subjects (students going to classes) were randomly approached by the interviewer. The interviewer first read the standardized script to the student (written on a piece of paper). Then the interviewer asked the subject to choose one envelope from a total of eight envelopes. Each envelope contained a different scenario and the subject's WTP was then solicited. All material was translated to Turkish on the spot by the interviewers. If the subject was an international student, the original English wording is used.

The following standardized script was described to every subject:

Very shortly, a new iPhone 4 without any mobile carrier contract (i.e., no SIM card) will go on sale for the Recommended Retail Prices (RRPs) of $\$ 599$ (16Gb) and $\$ 699$ (32Gb) in the US. How much would you be willing to pay in Turkish Lira (TL)? Before you consider the answer, there is a phone shop in town. They are planning to do a promotion in the near future. You pick up a queuing number and wait for customer service (like in a bank). Depending on your number, you may get a discount of $10 \%, 20 \%$ or no discount on a new iPhone 4 . The discount allocation is random and at the manager's discretion. There is no mention when the promotional offer will start or finish. Therefore, if you don't want to miss out on a new iPhone 4 while stocks last, you should not wait for the promotion to start. Furthermore, there is no purchase obligation if you don't hit the promotion jackpot. The promotion outcome is revealed to you before you make the purchase commitment. If you renege or walk away from your purchase, you can come back and try your luck again on another day (but not today). However, there is no guarantee stocks still last.

The survey is a $2 \times 2 \times 2$ factorial design with the three binary factors (Stocks, Refund and Promotion) listed in Table 2.

Table 2. Description of survey scenarios

\begin{tabular}{cccccc}
\hline & Scenario & Stocks & Refund & Promotion \\
\cline { 2 - 5 } & 1 & 1 & 0 & 0 \\
& 2 & 1 & 0 & 1 \\
3 & 1 & 1 & 0 \\
4 & 1 & 1 & 1 \\
& 5 & 0 & 0 & 0 \\
& 6 & 0 & 0 & 1 \\
7 & 0 & 1 & 0 \\
\hline
\end{tabular}

Stocks: $0=$ limited, $1=$ unlimited; Refund: $0=$ possible, $1=$ impossible; Promotion: $0=$ no, $1=$ yes.

The binary choices for "Stocks" are 0 (limited) or 1 (aplenty), for "Refund" are 0 (available) or 1 (not possible), and for "Promotion" are 0 (no future discounts) or 1 (future discounts possible). Various combinations of the three binary factors can lead to a total of eight possible different scenarios $(2 \times 2 \times 2=8)$. The following were these eight scenarios that the subjects could randomly chose:

\section{1): stocks are aplenty(1), refund is possible(0) but there is no promotion(0).}

Rationale: there is no possibility to pay any less, and there is nothing to gain by waiting. Hence, buy at RRP now and enjoy.

\section{2): stocks are aplenty(1), refund is possible(0) and there is promotion(1).}

Rationale: there is possibility to pay less. But even if you pay full RRP, you can demand a refund and try again later to see if you can hit the promotion jackpot. Therefore, to buy now doesn't constitute a commitment because 
you can always refund it. Hence, you should be happy to pay RRP now and enjoy. Note that there is a weak option here if there are transactions costs, such as travel to and from the premise.

\section{3): stocks are aplenty(1), refund is impossible(1) but there is no promotion(0).}

Rationale: there is no possibility to pay any less. There is nothing to gain by waiting. Hence, buy at RRP now and enjoy.

\section{4): stocks are aplenty(1), refund is impossible(1) and there is promotion(1).}

Rationale: there is possibility to pay less. Even if you don't hit the promotion jack port, you have the right to refuse purchase. However, to buy now constitutes a commitment since you cannot refund it. Therefore you will demand a premium for a loss of this option to buy cheap later. That means you are willing to pay less for the iPhone now. Alternatively, you are happy to wait for a promotion hit and enjoy later. The option is here. But it exists only when stocks are unlimited and you cannot take it back for a refund. It pays to wait for a promotion jackpot. The cost of delaying the reward (of enjoying the product), or DRD, is the discounting or lowering of the WTP.

\section{5): stocks are limited(0), refund is possible(0) but there is no promotion(0).}

Rationale: there is no possibility to pay any less. Since you may miss out on your favorite toy, it is better to buy at RRP now and enjoy.

\section{6): stocks are limited(0), refund is possible(0) and there is promotion(1).}

Rationale: there is possibility to pay less. If you don't hit the promotion jackpot, you can still buy now. You can make up any excuse for a refund and try again later. But you may miss out on your favorite toy because there may be no stock. To avoid the possibility of missing out, it is better to pay full RRP now and enjoy.

\section{7): stocks are limited(0), refund is impossible(1) but there is no promotion(0).}

Rationale: there is no possibility to pay any less. You may miss out on your favorite toy. Hence, buy at full RRP now and enjoy.

\section{8): stocks are limited(0), refund is impossible(1) and there is promotion(1).}

Rationale: there is possibility to pay less. However, if you don't hit the promotion jackpot, you cannot make up any excuse for a refund and try again later. Besides, you may miss out on your favorite toy. There may be no stock. To avoid the possibility of missing out, it is better to pay full RRP now and enjoy.

Notice that the subject only had to consider one of these eight scenarios based on the envelope they randomly chose. They would not see or consider the other seven scenarios. The rationales behind all scenarios were not explained to the subjects lest there be unwanted influences on the discounted WTP (DRD). Interviewers were told to read from the script verbatim without any improvisation. They were not allowed to make price recommendations. The exchange rate was approximately $1 \mathrm{USD}=1.5 \mathrm{TL}$ in May 2010. They were told to specifically discard uncooperative subjects who joked, offered ridiculous prices (too high, too low), who didn't understand or misunderstood the question, compared with android/blackberry phones, or couldn't afford to pay. Interviewers were not allowed to simply reject a subject based on their own judgement. Interviewers did not reveal other subjects' WTPs during the survey but they did aid in the subjects' calculation, e.g., exchange rate from $\$$ to TL or vice versa.

The interviewers' discretion did not create experimenter bias. Only six discards were reported out of 213 interviews (i.e., 207 usable observations).

The eight experimental scenarios may seem too complex and confusing. This was anticipated. Our strategy was to give a preamble first before each interview so that each subject was appropriately "placed". Then the subject was required to choose only ONE scenario from eight possibilities. They did not have to consider the other scenarios. This strategy had worked out well. Subjects did not report any complexity or confusion during the interviews.

Subjects were not interviewed in a quiet and controlled setting. We intentionally chose the busy cafeteria for this survey. Subjects were required to give an intuitive WTP without too much consideration. We believed that WTP was especially prone to mental manipulation when subjects "over-think". 


\section{Survey Results}

Our empirical strategy is to eliminate all possible potential confounding factors, i.e., subject's gender, survey day/time/venue, and interviewer bias (Tables 3 and 4). Then we conduct a $2 \times 2 \times 2$ factorial ANOVA to determine if the three factors (stocks, refund and promotion) and their combinations are producing significant effects (Tables 5 and 6) on the discounted WTPs. Finally, we isolate one specific combination (the RO) and calculate how much delayed discounting on WTP that this specific combination of factors can produce (Table 7).

Table 3 for the $16 \mathrm{G}$ model shows that all confounding variables, including subject gender, survey day/time/venue and interviewer, do not exhibit statistically significant differences $(p>.05)$. For example, WTPs from female and male subjects appear to be drawn from the same probability distribution with identical means (860.08 TL vs 852.50 TL) and Standard Deviations (SD). Ditto for survey day/time/venue and interviewer.

Table 3. ANOVA of survey findings for a 16 Gbyte memory iPhone 4

\begin{tabular}{|c|c|c|c|c|c|c|c|c|c|}
\hline 1. Sex of subject & female & male & & & & & & F-statistic & p-value \\
\hline Average WTP & 860.08 & 852.50 & & & & & & 0.26 & 0.61 \\
\hline 2. Survey day & 1 & 2 & 3 & 4 & 5 & & & & \\
\hline Average WTP & 842.27 & 840.00 & 853.04 & 879.13 & 868.33 & & & 1.07 & 0.37 \\
\hline 3. Survey time & 0800-0830 & $1200-1230$ & & & & & & & \\
\hline Average WTP & 855.00 & 858.68 & & & & & & 0.06 & 0.80 \\
\hline 4. Survey venue & $\mathrm{CLH}$ & FBE & & & & & & & \\
\hline Average WTP & 855.29 & 858.05 & & & & & & 0.04 & 0.85 \\
\hline 5. Interviewer & a & $\mathrm{b}$ & $\mathrm{c}$ & $\mathrm{d}$ & $\mathrm{e}$ & $\mathrm{f}$ & g & & \\
\hline Average WTP & 858.00 & 864.74 & 860.56 & 838.00 & 845.00 & 884.00 & 843.06 & 0.63 & 0.71 \\
\hline
\end{tabular}

For the $32 \mathrm{G}$ case (Table 4), WTPs solicited on different survey days also are not statistically different with almost identical means (1028.95 TL for day 1 vs 1017.37 TL for day 2 vs 1042.63 TL for day 3 vs $1028.68 \mathrm{TL}$ for day 4 vs 1018.10 TL for day 5). Similarly for survey time/venue, sex of subject and interviewer $(p>.05)$.

Table 4. ANOVA of survey findings for a 32 Gbyte memory iPhone 4

\begin{tabular}{|c|c|c|c|c|c|c|c|c|c|}
\hline 1. Sex of subject & female & Male & & & & & & F-statistic & p-value \\
\hline Average WTP & 1025.41 & 1028.54 & & & & & & 0.04 & 0.84 \\
\hline 2. Survey day & 1 & 2 & 3 & 4 & 5 & & & & \\
\hline Average WTP & 1028.95 & 1017.37 & 1042.63 & 1028.68 & 1018.10 & & & 0.37 & 0.83 \\
\hline 3. Survey time & 0800-0830 & $1200-1230$ & & & & & & & \\
\hline Average WTP & 1021.38 & 1032.20 & & & & & & 0.52 & 0.47 \\
\hline 4. Survey venue & CLH & FBE & & & & & & & \\
\hline Average WTP & 1021.35 & 1032.45 & & & & & & 0.55 & 0.46 \\
\hline 5. Interviewer & $\mathrm{a}$ & $\mathrm{b}$ & $\mathrm{c}$ & $\mathrm{d}$ & $\mathrm{e}$ & $\mathrm{f}$ & $\mathrm{g}$ & & \\
\hline Average WTP & 1006.25 & 1075.83 & 1026.67 & 1032.86 & 1026.36 & 1007.67 & 1024.29 & 1.30 & 0.26 \\
\hline
\end{tabular}

Tables 5 and 6 give the factorial analysis of the survey. They showed that all three RO factors (stocks, refund and promotion) and their interactions are statistically significant. Not only does each factor significantly affect the subject's discounting on WTP, their interactions are also highly significant. For instance, while limited stocks and unlimited stocks have significantly different WTP discounting, this discount difference depends significantly on, say, whether refund is available or not. The next step is to deduce from the experimental results which combination of the three factors results in the most significant WTP discount (by regression analysis). Since this is a $2 \times 2 \times 2$ factorial experiment, we have a total of eight possible combinations. The RO theory says 
that when the three factors are all in the positive (i.e., stocks are unlimited, refund is impossible and promotion is available), there exists an RO that leads to heavy discounting of delayed reward (i.e., future enjoyment of the new iPhone) in the form of discounted WTP.

Table 5. Dependent variable: WTP (16 Gbyte)

\begin{tabular}{lcccc}
\hline Source & DF & Type III SS & F Value & $\operatorname{Pr}>$ F \\
\hline Stocks & 1 & 50710.95 & 32.31 & $<.0001$ \\
Refund & 1 & 16354.28 & 10.42 & 0.0017 \\
Stocks*Refund & 1 & 29147.14 & 18.57 & $<.0001$ \\
Promotion & 1 & 79541.96 & 50.69 & $<.0001$ \\
Stocks*Promotion & 1 & 58974.80 & 37.58 & $<.0001$ \\
Refund*Promotion & 1 & 33727.67 & 21.49 & $<.0001$ \\
Stocks*Refund*Promotion & 1 & 31139.60 & 19.84 & $<.0001$ \\
Error & 102 & 160067.97 & & \\
\hline Corrected Total & 109 & 640229.32 & & \\
\hline
\end{tabular}

Table 6. Dependent variable: WTP (32 Gbyte)

\begin{tabular}{lcccc}
\hline Source & DF & Type III SS & F Value & Pr $>$ F \\
\hline Stocks & 1 & 35669.71 & 14.33 & 0.0003 \\
Refund & 1 & 20250.02 & 8.14 & 0.0054 \\
Stocks*Refund & 1 & 14983.61 & 6.02 & 0.0161 \\
Promotion & 1 & 95951.72 & 38.55 & $<.0001$ \\
Stocks*Promotion & 1 & 56559.87 & 22.73 & $<.0001$ \\
Refund*Promotion & 1 & 37646.68 & 15.13 & 0.0002 \\
Stocks*Refund*Promotion & 1 & 15830.42 & 6.36 & 0.0134 \\
Error & 89 & 221497.09 & & \\
\hline Corrected Total & 96 & 522527.84 & & \\
\hline
\end{tabular}

\section{Regression Analysis}

In Table 7, the $Q_{i}$ 's are the seven dummy variables for scenarios two to eight. Scenario one is the intercept. Regression is estimated twice-once each for the $16 \mathrm{G}$ and $32 \mathrm{G}$ iPhones. Since the WTP residuals may have unequal variances conditional on the eight scenarios, we employ a heteroscedastic-consistent estimation procedure for the standard errors (White, 1980). The $\beta_{i}$ 's calculate the effect of each scenario on WTP as compared to scenario one. We have estimated two regressions for both iPhone models. Regression 1 contains 
dummies for all scenarios. In regression $2, Q_{i}$ only contains the dummy for scenario four (where the RO is) while all the other scenarios are grouped into the intercept. This allows us to calculate the DRD (effect of the RO on WTP) as compared to the average of all other non-DRD scenarios (no RO). Therefore, $\beta_{4}$ in regression 2 is the estimated value of the purchase option or the estimated magnitude/strength of DRD.

Table 7. Regression analysis dependent variable $=$ WTP

\begin{tabular}{|c|c|c|c|c|c|c|c|c|}
\hline \multirow[b]{3}{*}{ regressor } & \multicolumn{4}{|l|}{ Regession 1} & \multicolumn{4}{|c|}{ Regression 2} \\
\hline & 16 Gbyte & & 32 Gbyte & & 16 Gbyte & & 32 Gbyte & \\
\hline & coeff & st err^ & coeff & st err^ & coeff & st err ${ }^{\wedge}$ & coeff & st err^ \\
\hline intercept & $894.64 * *$ & 8.81 & $1062.50 * *$ & 14.66 & $890.06 * *$ & 3.21 & $1047.68 * *$ & 5.15 \\
\hline Q 2 & $-32.77 *$ & 13.36 & $-47.50^{*}$ & 21.10 & & & & \\
\hline Q 3 & 12.23 & 10.16 & 11.50 & 18.25 & & & & \\
\hline Q 4 & $-163.77 * *$ & 16.40 & $-169.42 * *$ & 24.66 & $-159.19 * *$ & 14.20 & $-154.60 * *$ & 20.49 \\
\hline Q 5 & -2.37 & 10.39 & -9.50 & 16.25 & & & & \\
\hline Q 6 & -8.73 & 10.85 & -10.28 & 20.17 & & & & \\
\hline Q 7 & 7.58 & 8.92 & 0.58 & 16.96 & & & & \\
\hline Q 8 & -1.64 & 10.28 & -28.65 & 20.03 & & & & \\
\hline$R$-square & 0.75 & & 0.58 & & 0.72 & & 0.52 & \\
\hline F-statistic & 43.71 & & 17.28 & & 277.73 & & 100.86 & \\
\hline p-value & 0.00 & & 0.00 & & 0.00 & & 0.00 & \\
\hline observations & 110 & & 97 & & 110 & & 97 & \\
\hline
\end{tabular}

* - statistically significant at $5 \%$ level; ** - at $1 \%$ level

$\wedge$ - heteroscedastic-consistent standard errors (White, 1980)

coeff - coefficient; st err - standard error; Q - scenario

Intercept $=$ Q 1

Regression $1=$ all scenarios represented in regression

Regression 2 = only Q 4 is regressed, all other scenarios are represented by intercept

Coefficient for Q 4 in regression 2 = estimated discount in WTP with RO (magnitude of DRD)

Intercept for regression 2 = estimated WTP without RO

The $R^{2}$ is relatively high for a cross-sectional study. Regression 1 tells us that scenario four gives an expected significant difference (negative) in effect on WTP as compared to scenario one. The surprise is that scenario two also shows up as having a significantly different effect than scenario one, at the $5 \%$ level. This is the case for both $16 \mathrm{G}$ and $32 \mathrm{G}$ iPhones.

Scenario two is the closest to having an RO (apparent DRD). In theory, it shouldn't. The scenario allows the consumer to delay purchase (unlimited stock) and offers uncertain price (through the promotional discount) but the purchase is refundable (reversible). There is no valuable option here. Even if the consumer does not hit the promotion jackpot, he can always demand a refund and try again later to see if he qualifies for the discount. Moreover, he can do this ad infinitum. Therefore, he is happy to pay the full RRP now. He can start enjoying the iPhone right away, knowing full well that the discount will be there for the taking. However, some subjects believed the certainty of discount could be translated to a lower WTP for the phone now. This resulted in a decrease of approx. $33 \mathrm{TL}$ for the $16 \mathrm{~Gb}$ model and $48 \mathrm{TL}$ for the $32 \mathrm{~Gb}$ model.

Scenario four is where the RO (actual DRD) exists. Here the purchase can be delayed and there is a possibility of discount, but the purchase is non-refundable. Therefore the subjects were not willing to pay the full RRP for the phone now. They knew they could never try again later to qualify for the promotional discount. To buy now meant to kill the option to buy cheaper later. As a result, subjects demanded a compensation for the loss of this 
option. This resulted in a decrease in WTP (DRD) of approx. $164 \mathrm{TL}$ for the $16 \mathrm{~Gb}$ phone and $169 \mathrm{TL}$ for the 32 Gb phone, when compared to scenario one subjects (Regression 1, Table 7). Looking at Regression 2 (Table 7), scenario four subjects (with the RO) demanded a drop in WTP (value of the RO or DRD) of approximately 159 $\mathrm{TL}$ for the $16 \mathrm{~Gb}$ phone and $155 \mathrm{TL}$ for the $32 \mathrm{~Gb}$ phone, when compared to all other subjects. On average, all subjects (sans scenario four) are willing to pay $890 \mathrm{TL}$ for the $16 \mathrm{G}$ phone and $1048 \mathrm{TL}$ for the $32 \mathrm{G}$ phone. On the contrary, scenario four subjects (holders of the RO and DRD) are only willing to pay $731 \mathrm{TL}$ (890 TL-159 $\mathrm{TL})$ and $893 \mathrm{TL}$ (1048 TL-155 TL), respectively.

Interestingly, the value of the option (magnitude of the DRD) equates to approximately halfway between the savings for a $10 \%$ discount and a $20 \%$ discount (the two promotional offers). This is the case for both the $16 \mathrm{G}$ and $32 \mathrm{G}$ iPhones. In other words, subjects are shrewd enough to demand a reduction of at least $10 \%$ for the loss of future discount possibility, while also realistic enough not to demand the maximum discount possibility (20\%). It may be a while (may be never) before he sees the $20 \%$ discount offer. In the meantime, he cannot enjoy the iPhone while he waits.

\section{Conclusions and Research Implications}

In this study, we introduce the Real Option (RO) theory as a competing hypothesis towards an explanation of DRD. Instead of soliciting the actual behavioral manifestation of the sliding scale of DRD in an experimental setting, we conducted a small-scaled survey among college students. We wanted to see if severe DRD can be observed as an intuitive verbal response without the students being aware of the survey's actual intended purpose.

The survey results suggest that when certain pre-conditions (uncertainty, irreversibility and delay) prescribed by RO theory are satisfied, the subjects intuitively give a response that is consistent with the severe form of DRD as well as with predictions from RO theory. Specifically, the non-option scenarios (one to eight except four) resulted in WTPs that approximated the RRP. The option scenario (four) led to discounted WTPs roughly in the order of the promotional discount, as the theory predicted. Hence, the survey results supported our assertion that the three factors of uncertainty, irreversibility and delay must be present simultaneously to create a significant DRD (in the form of discounted WTP).

Therefore, this makes the RO theory a potential candidate to explain severe DRD. In the process, it also establishes the three required pre-conditions in RO as factors affecting DRD.

In various presentations of our results, we have encountered the following constructive comments which have helped us refine the paper in its current format:

1) Speculative explanation-The explanation of delay discounting by real option is an entirely novel concept, and as such is necessarily speculative. We agree that speculating about what the subjects were thinking during the interviews was fallacious, especially since we did not ask follow-up questions to get at this. Hence, we follow a positive approach in which we matched the observations with predictions from the RO theory, to see if they fit.

2) Our experiment is very complicated - We have greatly simplified the experiment to meet the specifications of the RO theory. To avoid potential confusion to subjects, we ordered the interviewers to stick to the script verbatim and ask subjects to consider only ONE scenario (out of a total of eight).

3) The interviewers' instructions appear too confusing-The purchase delay was never specified (i.e., short or long delay) in order to introduce an element of uncertainty. Subjects were asked to consider a $16 \mathrm{G}$ or $32 \mathrm{G}$ iPhone from the outset. No confusion was reported. The discount is random (i.e., $0 \%, 10 \%$ or $20 \%$ ). This is the uncertainty, a pre-condition for the theory to hold. Subjects could also refuse purchase. This is to introduce an element of reversibility, again required by theory.

4) Interviewers were untrained volunteers-The interviewers were trained to follow a standardized script. The interviewers were in fact the subjects' fellow students to minimize potential apprehension, which might heavily influence a financial decision (WTP). They were ordered to keep interactions to a minimum. The discarding of extreme data was not a problem. Only six cases were reported out of 213 interviews.

5) More variables were not held constant-For example, "purchase delay" cannot be fixed in advance (as required by theory). We offered two phone types because they were the actual product offerings from Apple, Inc. at the time. We wished to see if another category of essentially the same product might affect the results.

6) Parametric analysis within given subjects were not undertaken-Delay discounting is a universal phenomenon that is a matter of degree (whether one discounts a little or a lot), and not a matter of dichotomy (whether one 
discounts or not). For example, we could have offered a continuous discount from $0 \%$ to $20 \%$, and measured the corresponding decrease in WTP. The only choices of $0 \%, 10 \%$ or $20 \%$ were less desirable. This could be accommodated in future experiments. For now, we believe these choices would suffice to bring out the measurable decrease in WTP. For the $2 \times 2 \times 2$ design, the analysis cannot be parametric since the three factors are dichotomous.

7) Decision making is typically a parametric process-For example, there should be an Instrumental Variable (IV) that continuously affects how much a subject would discount. However, in this case, the real option is either present or not. It appears only if the three pre-conditions of delay, uncertainty and irreversibility are present. Perhaps the size of the option matters. For example, higher uncertainty results in a larger option. A proper parametric analysis of this kind would need further enhancements of the present experiment. As a first step, we show that the real option matters. How much it matters is a subject for further research.

8) Improper conceptualization of delay discounting-Delayed reward discounting is a general phenomenon. Susceptibility to this behavior is a matter of degree and not a matter of whether one discounts or not. A proper study of delay discounting should follow a parametric analysis of IVs on a subject's discount response. In our experiment we were dealing with a dichotomous factor that is either present or not (real option). Perhaps the strength of this factor (when it is present) would indicate whether an individual would be at risk of behavioral maladies. It is an important research direction. Here we have shown that this factor matters. How much it matters awaits further research.

\section{Acknowledgements}

I thank participants of the $10^{\text {th }}$ International Marketing Congress (20-22 January, 2011, ESCP Europe, Paris) for their enlightening discussion. Two anonymous reviewers, and Greg Madden and Amy Odum of the Journal of Experimental Analysis of Behavior gave constructive comments that greatly strengthened the manuscript.

I am grateful for the financial support from the Department of Statistics and Actuarial Science at the University of Hong Kong.

\section{References}

Ainslie, G. W. (1975). Specious reward: A behavioral theory of impulsiveness and impulsive control. Psychological Bulletin, 82(4), 463-496. https://doi.org/10.1037/h0076860

Ainslie, G. W. (2001). Breakdown of Will. Cambridge, MA: Cambridge University Press. https://doi.org/10.1017/CBO9781139164191

Ainslie, G. W. (2010). Picoeconomics: The Strategic Interaction of Successive Motivational States within the Person (Studies in Rationality and Social Change). Cambridge, MA: Cambridge University Press.

Bickel, W. K., Odum A. L., \& Madden G. J. (1999). Impulsivity and cigarette smoking: Delay discounting in current, never and ex-smokers. Psychopharmacology, 146, 447-454. https://doi.org/10.1007/PL00005490

Bickel, W. K., Jarmolowicz, D. P., Mueller, E. T., Koffarnus, M. N., \& Gatchalian K. M. (2012). Excessive discounting of delayed reinforcers as a trans-disease process contributing to addiction and other disease-related vulnerabilities: Emerging evidence. Pharmacology \& Therapeutics, 134(3), 287-297. https://doi.org/10.1016/j.pharmthera.2012.02.004

Dickman, S. J. (1990). Functional and dysfunctional impulsivity: Personality and cognitive correlates. Journal of Personality and Social Psychology, 58(1), 95-102. https://doi.org/10.1037/0022-3514.58.1.95

Dixit, A. (1992). Investment and hysteresis. Journal of Economic Perspectives, 6(1), 107-132. https://doi.org/10.1257/jep.6.1.107

Dixit, A., \& Pindyck, R. S. (1994). Investment Under Uncertainty. Princeton NJ: Princeton University Press.

Dixit, A., Pindyck, R. S., \& Sodal, S. (1999). A markup interpretation of optimal investment rules. The Economic Journal, 109, 179-189. https://doi.org/10.1111/1468-0297.00426

Harrison, J. M. (1985). Brownian Motion and Stochastic Flow Systems. New York: John Wiley.

Harrison, J. M., \& Kreps, D. (1979). Martingales and arbitrage in multi-period Securities markets. Journal of Economic Theory, 20, 381-408. https://doi.org/10.1016/0022-0531(79)90043-7

Hendrickx, L., Poortinga, W., \& van der Kooij, R. (2001). Temporal factors in resource dilemmas. Acta Psychologica, 108(2), 137-164. https://doi.org/10.1016/S0001-6918(01)00032-4 
Herrmann, A., Heitmann, M., Morgan, R., Henneberg, S. C., \& Landwehr, J. (2009). Consumer decision making and variety of offerings: The effect of attribute alignability. Psychology and Marketing, 26(4), 333-358. https://doi.org/10.1002/mar.20276

Kahneman, D., \& Tversky, A. (2000). Choices, Values and Frames. Cambridge, MA: Cambridge University Press.

MacKillop, J., Amlung, M. T., Few, L. R., Ray, L. A., Sweet, L. H., \& Munafò, M. R. (2011). Delayed reward discounting and addictive behavior: A meta-analysis. Psychopharmacology, 216(3), 305-321. https://doi.org/10.1007/s00213-011-2229-0

Madden, G. J., Francisco, M. T., Brewer, A. T., \& Stein, J. S. (2011). Delay discounting and gambling. Behavioral Processes, 87, 43-49. https://doi.org/10.1016/j.beproc.2011.01.012

Mazur, J. E. (1989). Theories of probabilistic reinforcement. Journal of Experimental Analysis of Behavior, 51, 87-99. https://doi.org/10.1901/jeab.1989.51-87

Mazur, J. E. (2001). Hyperbolic value addition and general models of animal choice. Psychological Review, 108(1), 96-112. https://doi.org/10.1037/0033-295X.108.1.96

Rachlin, H. (2000). The Science of Self-Control. Cambridge, MA: Harvard University Press.

Silberberg, E., \& Suen, W. (2001). The Structure of Economics. McGraw-Hill International.

Sozou, P. D. (1998). On hyperbolic discounting and uncertain hazard rates. Proceedings of the Royal Society, 265, 2015-2020. https://doi.org/10.1098/rspb.1998.0534

Thaler, R. H., \& Benartzi, S. (2004). Save More Tomorrow ${ }^{\mathrm{TM}}$ : Using behavioral economics to increase employee saving. Journal of Political Economy, 112(1), S164-S187. https://doi.org/10.1086/380085

Tversky, A., \& Shafir, E. (1992). Choice under conflict: The dynamics of deferred decision. Psychological Science, 3, 358-361. https://doi.org/10.1111/j.1467-9280.1992.tb00047.x

White, H. (1980). A heteroskedasticity-consistent covariance matrix estimator and a direct test for heteroskedasticity. Econometrica, 48, 817-838. https://doi.org/10.2307/1912934

\section{Note}

Note 1. Although the $3^{\text {rd }}$ person singular pronoun he/his was used throughout to describe the subject/consumer, he was intended to be gender-neutral.

\section{Copyrights}

Copyright for this article is retained by the author(s), with first publication rights granted to the journal.

This is an open-access article distributed under the terms and conditions of the Creative Commons Attribution license (http://creativecommons.org/licenses/by/4.0/). 